\title{
Sustainable energy transition framework for unmet electricity markets
}

\author{
Benjamin Batinge ${ }^{\mathrm{a}, *}$, Josephine Kaviti Musango ${ }^{\mathrm{a}}$, Alan C. Brent ${ }^{\mathrm{b}, \mathrm{c}}$ \\ ${ }^{a}$ School of Public Leadership, Urban Modelling and Metabolism Assessment (uMAMA), Centre for Complex Systems in Transition (CST), Stellenbosch University, South \\ Africa \\ ${ }^{\mathrm{b}}$ Department of Industrial Engineering, Centre for Renewable and Sustainable Energy Studies (CRSES), Urban Modelling and Metabolism Assessment (uMAMA), \\ Stellenbosch University, South Africa \\ ${ }^{\mathrm{c}}$ Sustainable Energy Systems, Engineering and Computer Science, Victoria University of Wellington, New Zealand
}

\section{A R T I C L E I N F O}

\section{Keywords:}

Energy transition

Electricity transition

Renewable energy

Sustainability transition

Unmet electricity market

\begin{abstract}
A B S T R A C T
Efficient energy supply is a means for people to gain access to a wide range of energy-related services. In unmet energy markets where energy supply is inadequate or lacking, such services, and the resulting benefits, are seldom attained. This has prompted research on energy transition, specifically a transition to renewable energy, to rapidly diffuse energy access in these regions. Existing energy transition frameworks are predominantly contextualised in developed economies, with little evidence of their applicability in the context of developing countries. This paper proposed an energy transition framework for the unmet electricity markets, after conducting a systematic review of the literature on energy transitions, specifically relating to sustainable transitions of electricity systems. Contextual limitations observed in the energy transition literature included market demand, scale of energy infrastructure, type of energy resource, transition duration, novelty of opportunities, and level of external influence. An energy transition framework for unmet electricity markets was subsequently conceptualised. The key characteristics of this modified transition framework are: (i) traditional technology; (ii) defunct deceleration; (iii) a niche technology curve; (iv) landscape support for niches; and (v) new regime condensation (emergence). Contextual awareness in designing policy frameworks for energy transition is essential to achieve sustainable energy for all, particularly in unmet electricity markets.
\end{abstract}

\section{Introduction}

The developing world, especially Africa and Asia, remains the most energy-deficient region in many and diverse ways (IEA, 2011). This ranges from the lack of access to electricity, which undermines the quality of health and education services (Kanagawa and Nakata, 2008), as well as failing to meet essential services, such as electronic communication, lighting, heating, and transport (IEA, 2011). Transition in energy supply is increasingly becoming a prerequisite for addressing the growing diversity in end-use energy needs, not just in the developing world, but also in industrialised countries. Grubler (2012) emphasises this need by questioning the sustainability of current energy systems. He points out that these systems are simply unsustainable and calls for the 'next' energy transition. Miller et al. (2015) reiterate that future energy systems require major policy changes, especially in industrial economies. Further elaborating on the urgent need for transition in energy, Giddens (2009) posits that humanity is approaching the carbon emission threshold, where the global economy would exceed the point of no return if no action were taken. He based this postulation, which he termed as the climate paradox, on the maximum emission target stipulated by the UNFCCC (1992). The need for the inclusion of alternative energy sources to supplement current infrastructure to meet future energy needs is thus inevitable.

Transition has broad connotations across disciplines, and literature on transition spans different domains, including: demographic studies (Caldwell, 1976; Chesnais, 1992; Kirk, 1996; Meir, 1986), health (Frenk et al., 1991; Mackenbach, 1994; Omran, 1971), politics, power and democracy (Adler and Webster, 1995; De Soysa et al., 1997; Lemke and Reed, 1996; Linz and Stepan, 1996; Offe and Adler, 1991), economic and market forces (Nee, 1989; Roland, 2002; Weitzman, 1993), environment (van den Bergh, 2007), and energy (Kern and Smith, 2008; Meadowcroft, 2009; Meadows et al., 1972). This paper examines transitions in the energy sector, with specific focus on electricity generation. Transitions, particularly in infrastructural systems, do not occur easily (Verbong and Geels, 2010). Transition in fundamental systems is often met with inertia, and seldom come about in as timely and orderly fashion as intended. Large-scale transitions, such as of energy systems infrastructure, are often beyond the control of a single

\footnotetext{
* Corresponding author.

E-mail address: benjaminb50@gmail.com (B. Batinge).
} 
sector or entity, whether private markets or public agencies (Davison et al., 2000). The condition for significant transition is not just a change in technology, but also includes changes in political regulations, pricing schemes, and end-user behaviour (Sovacool, 2016). This was found to be the case in large transitions, such as a move to renewable electricity (Painuly, 2001; Sovacool, 2009), and the introduction of electric vehicles (Nielsen et al., 2015; Sovacool and Hirsh, 2009). In the wake of this growing need for transition, a number of transition scholars have attempted to prescribe an appropriate transition framework for the energy sector. The frameworks also extend to transition paradigms that focus on the sustainability of resources.

One of the present transition frameworks pertaining to energy is the multi-level perspective. It is, however, predominantly contextualised in developed economies where energy, in the form of electric power for electricity services, has reached the entire population (Fouquet, 2010; Geels, 2002, 2005a; Kemp et al., 2007b; Sarrica et al., 2016; Shackley and Green, 2007). The implication is that this framework might not be suitably applicable to unmet electricity markets, such as in Africa. This is because of the significant differences between developed and developing countries in areas such as economic, social, technical, and geographical status, among other factors. Infrastructural development in developing countries is at an infantile stage (Tukker, 2005). As a result, infrastructural lock-in and path dependence that favours particular socio-technical alignments are either weak or non-existent. It must be mentioned, however, that political, socio-cultural, and financial factors might inhibit transition in unmet energy markets, and account for a lock-in or path dependence. Some transition literature also defines transitions as including the overhaul of large physical infrastructure, such as power plants (Dijkema and Basson, 2009), in an attempt to migrate to novel technologies, such as solar photovoltaic power. Because of the largely unmet electricity demand in Africa, adoption of renewable energy as a means of providing electricity, may become obligatory, rather than a choice. In addition, transitioning to renewable energy technologies may not necessarily require centralised large physical infrastructure, especially in the context of achieving sustainable energy for all, but could involve a more decentralised system.

The study seeks to propose a sustainable energy transition framework, especially one representative of unmet electricity markets, to: (i) ensure universal access to electricity amid concerns regarding the scarcity of energy resources; and (ii) protect the environment in the face of growing energy need and demand. This study is therefore based on significant contextual differences between industrialised countries and those of Africa, and questions the applicability of industrialised nations' energy transition frameworks in the African context. It addresses this theoretical and empirical gap by investigating and developing a contextual energy transition framework for unmet electricity markets.

The rest of the paper is organised as follows. section 2 describes the methodological approach employed in the study, and is then followed by a literature review of energy transition frameworks in section 3 . Section 4 presents a brief discussion of the theoretical foundation of the frameworks. Section 5 highlights the limitations of the present energy transition frameworks for unmet markets, while section 6 summarises the features of the modified transition framework. Section 7 draws conclusions based on the findings.

\section{Method}

The objective of the study was achieved by conducting a systematic review of literature from peer reviewed journal articles and grey research, including material outside traditional peer reviewed academic literature. The choice of this method was to ensure that significant energy and transition literature was considered. This method was useful for revealing similar studies because of its ability to uncover publications that shared key search queries. The grey literature in this paper includes policy statements, dissertations, conference proceedings, government reports, and organisational research publications related to transitions in the energy sector, specifically those pertaining sustainable transitions in electricity systems. The literature reviewed to identify the gaps and subsequent framework conceptualisation, spanned the period from 1970 to 2016. The choice of timespan was to enable as exhaustive a study of the literature on energy and electricity sector transitions as possible, as most of the research on this topic has occurred over the past forty years. Prior to the 1980s, energy transition, especially to renewable energy, was not a prominent topic of academic discourse, hence the limited available literature (Araújo, 2014). Very few scholars, most notably Meadows et al. (1972) demonstrated concern for the subject. Climate change was thus not considered a collective global responsibility until the 1990s, when the first climate treaty - the United Nations Framework Convention on Climate Change (UNFCCC) - acknowledged the existence of global warming and surmised its link to greenhouse gas emissions (UNFCCC, 1992). Similarly, alternative renewable technologies such as solar photovoltaic (PV) received little attention, as fossil fuel production boomed.

A qualitative approach to gathering data was adopted, and the search focused on text documents. Information was gleaned from published books, grey literature, and peer reviewed articles from the following Internet databases: Google Scholar, SCOPUS, Science Direct, and direct Google searches. Although the listed search databases are prominent publishers of energy research, they are not the only sources of energy literature. In order to compensate for this limitation, conscious effort was made to broaden the search scope, hence, the inclusion of direct Google search. Specific key phrases namely: energy transition, electricity transition, renewable energy, sustainability transition, and unmet electricity market were used, not as one query but as separate and combination queries. The use of these individual phrases, or in combinations of two or more in the searches, ensured sufficient content analysis of past studies on the subject matter, and thus offered insights on theoretical and contextual uniqueness to inform the framework design. The search was conducted without any geographic demarcation, and included publications up to the end of 2015. In all, 141 publications were found from the Internet database mentioned, and were classified according to the year of publication (see Fig. 1). After examining the publications, four transition frameworks namely: transition management, socio-technical transition, innovation systems and Strategic Niche Management were found and discussed. These frameworks were mainly found in 14 publications, which are captured in section 3 of this paper. Two transition theories: complex systems and evolutionary systems were also identified in the literature. Analysis of the textual data was carried out by way of critical examination of the literature. The frameworks were then juxtaposed in the context of an unmet energy market, to assess their empirical suitability. We developed a modified energy transition framework, based on the dynamic multi-level perspective of technological transitions by Geels (2002), for unmet electricity markets, taking into account the unique features of unmet energy markets identified in Africa. A key challenge in this process was how to filter the extensive literature to focus on those publications that addressed transition approaches and framework issues. Fig. 1 represents the number of articles and year of publication after scaling and refining the literature according to the criteria described.

The results from the systematic review were discussed within four broad themes: (i) energy transition frameworks; (ii) theoretical foundation of the energy transitions frameworks; (iii) limitations of present transition frameworks in the context of Africa; and (iv) a modified transition framework for unmet electricity markets.

\section{Energy transition frameworks}

Like other disciplines, the energy sector has attracted varied academic discourse over the past few decades. This led to the formulation of hypotheses and the eventual development of frameworks and approaches to assess energy system transitions. The energy transition frameworks and approaches that emerged through empirical and 


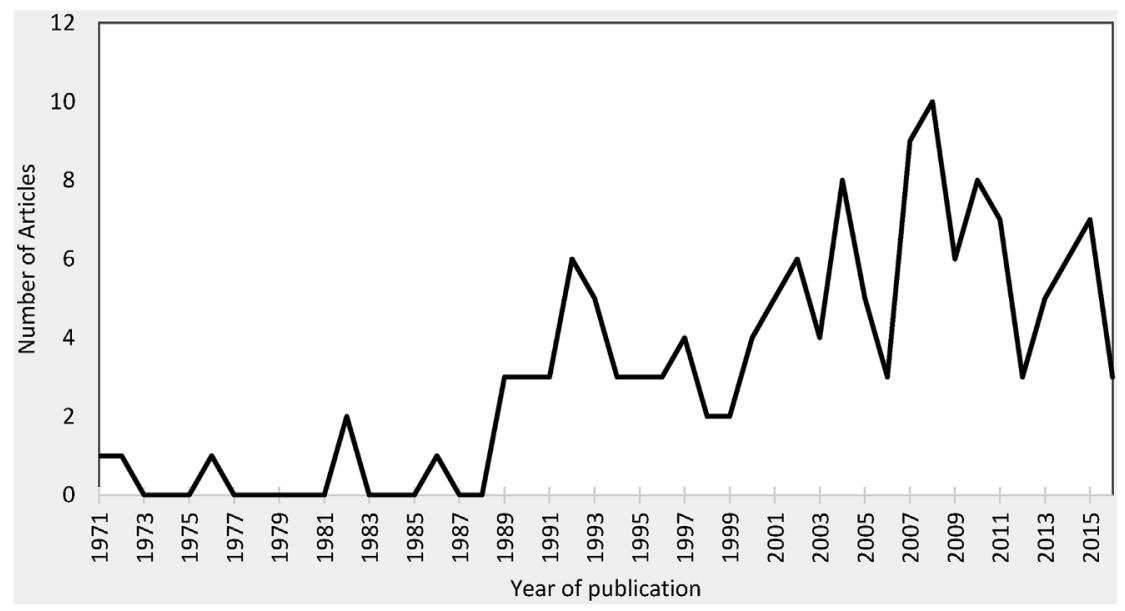

Fig. 1. Number of citations per year shortlisted in the systematic review.

theoretical studies include: transition management (Kemp and Rip, 1998; Loorbach and Rotmans, 2010; Rotmans et al., 2001), the multilevel perspective (Geels, 2002, 2011; Kemp et al., 2001), innovation systems (Bergek et al., 2008; Carlsson et al., 2002; Edquist, 2011; Hekkert et al., 2007; Jacobsson and Bergek, 2011), and Strategic Niche Management (Kemp et al., 1998; Raven and Geels, 2010; Smith, 2007). The frameworks, though diverse in focus and emphasis, recognise the energy sector as a dynamic field of multiple stakeholders that can be categorised into upstream suppliers, downstream consumers, and independent stakeholders influencing both supply and demand dynamics. These frameworks are discussed in detail under the subsections that follow; starting with transition management, followed by socio-technical transition and the multi-level perspective, then innovation system, and finally the Strategic Niche Management.

\subsection{Transition management}

A fundamental goal in managing a transition is ensuring that changes in systems are sustainable, future-oriented, and adaptive. This ensures that the relationship or linkage between technical services and social functions is not destroyed (Kemp, 2010). Different challenges may arise in the process of transitioning from one technology to another. This is the critical stage where knowledge of transition management is of enormous significance. The concept of transition management is traced back to Ackerman (1982), who defined it as a 'systematic study and design of an organisation's strategy and supporting structures, followed by the formal planning, implementation and monitoring of the changes required'. This emphasises that changes in socio-technical systems are not a result of a natural evolutionary process but, instead, engineered by human activity (Kemp et al., 2001). Transition in technical systems emanates from management decisions pioneered by improved end-use service needs. The goal of transition management, therefore, is to institute optimal policies that systematically result in change in the socio-technical system (Kern and Smith, 2008).

Management is a crucial aspect of organisations, especially within large-scale socio-technical systems in transition. Management within complex socio-technical systems, such as energy systems, is different and more compelling compared to, for example, the management of human resources in an organisation. Nonetheless, application of the basic management principles namely planning, organising, staffing, motivating, and monitoring, remain essential. Expertise in these managerial principles, as well as fundamental knowledge of the sociotechnical structure and its accompanying complexities, are prerequisites in order for transition managers to oversee socio-technical systems during a transition (Chappin and Dijkema, 2010). Research on transition management is based on case studies (Geels, 2002, 2005a), and management processes (Rotmans et al., 2001; Rotmans and Loorbach, 2009).

Transition management offers a remedy to recurring problems that are not easily solved by conventional means, in areas such as energy, agriculture, construction, and transport (Loorbach, 2010). Transition management is most required in the transition from one energy source such as fossil fuel, to another, such as renewable energy sources. The interaction between society (energy end-users) and technology (provision of energy services e.g. lighting, heating, cooking, cooling) requires transition management to maintain a balance and ensure proper adjustment and adaptation.

\subsection{Socio-technical transition and the multi-level perspective}

Transitions occur within both small- and large-scale infrastructure. Mitchell (2008) contends that transition involving large-scale infrastructure, such as energy, often requires a change in ideological stance, as well as the political environment. The responsibility falls to policymakers to access and manage the changes anticipated from potential transitions (van den Bergh, 2007). The interaction between society and technology varies, depending on a range of factors, including the stage of development, and the unique benefits the technology offers society. Kemp and Rip (1998) proposed the concept of socio-technical transition based on the co-evolutionary nature of technology, and its interaction with society in different spheres. Socio-technical change involves a reconfiguration and rearrangement of core elements to establish new links of interconnectedness within a system (Geels, 2002). This study expanded the interplay between society's electricity needs e.g. lighting, cooking, heating, and cooling, and the technical means e.g. oil, gas, coal, nuclear, hydroelectricity, wind, and solar, through which electricity services are provided, given that downstream end-use largely drives the transition in energy systems (Grubler, 2012).

Research on transition in the energy sector, unlike other disciplines, is concentrated in specific geographic locations. Over half of the energy transition literature is traceable to three countries: The Netherlands, the United Kingdom, and the United States of America. The present literature addressing large-scale social and technical infrastructural change or transition, such as energy or electricity (Elzen et al., 2004; Geels, 2002, 2004a, 2005b; Geels and Schot, 2007), fully or partially, adopts the socio-technical multi-level perspective framework developed by Geels (2002).

The multi-level perspective remains the most common socio-technical transition framework used in sustainable transition research literature (Geels, 2002, 2004a; Kemp et al., 2007b). It highlights the different levels of society's interaction with technology. The connection between technology and society is acknowledged and substantiated in 
fields such as actor-network theory (Callon, 1999; Law, 1992). From an evolutionary standpoint, van den Bergh (2007) demonstrates the linkage between innovation and behavioural routines, as well as organisational structures. The multi-level perspective Geels (2002) proposed, depicts the relationship of the three different levels of system innovation and the potential outcome of their interaction.

The multi-level perspective of innovation systems suggests that niche technologies encounter extensive competition from regime technologies that already possess a greater market share and benefit from scale of production. Niche technologies that survive the stiff competition of the regime create instability in the market, facilitated by pressure from landscape development on regime technologies (Geels, 2005a). A new technological regime consequently emerges from the interaction between the landscape, regimes and niches in the technology diffusion path.

\subsubsection{Landscape}

Concerns over the exploitation and depletion of fossil energy resources emerged in the latter half of the twentieth century. Early scholarly works relating to energy resources include the limits to growth (Meadows et al., 1972) and advocacy for a green economy transition (Pearce et al., 1989). It would take decades before the global community initiated efforts to collaborate on the potential problems of continued fossil dependency. The energy landscape, the dynamic space where the discourse of influencing regime and niche development trajectories takes place, was thus established. Geels (2004b) considers this landscape as a collection of cultural values, political coalitions, environmental programmes, growth, and economic developments that do not easily change. Landscape refers to an independent exogenous space that is not affected by the activities of the regime or niche.

The socio-technical landscape plays a crucial role in the length of a regime's reign and the speed at which a niche technology advances to overthrow a regime. The United Nations, through its Conference of Parties (COP) for example, tasks member countries to cut emissions by reducing their fossil fuel consumption and promoting the use of sustainable fuel from renewable sources. The effect of a global landscape policy stance such as COP24, trickles down to influence society's energy consumption behaviours and indirectly shapes opinions on fossil fuels and receptivity to renewable energy. European policies, especially those pertaining to energy, climate, carbon tax and trading, might also have a spill over effect on the development of energy in Africa. In fact, some of these policies have led to funding projects for Africa from Europe, such as the European Union Electrification Financing Initiative, the Africa-EU Renewable Energy Programme, the Sustainable Energy Fund for Africa, among others, to support clean energy in Africa. An understanding of the socio-technical landscape is relevant to examine how external entities pressure or support an emerging technology, influences society's perception and adoption of such technology.

\subsubsection{Regimes}

A regime refers to the infrastructure prevailing at a given time (Geels, 2002). The regime frontier, or the meso-level, is between the socio-technical landscape and the socio-technical niche. The dominant energy infrastructure, through which energy services are met, forms the regime. Socio-technical regimes often consist of large-scale infrastructure and exhibit lock-in, and path dependence (Geels, 2005a). Transitioning from a regime often poses a great challenge, given the large investment in the form of power cables, transformers, and especially power plants, in the case of energy or electricity infrastructure (Verbong and Geels, 2010).

The challenge of changing socio-technical systems is embedded in their very characteristics, in that they are an embodiment of strong and stable infrastructures and institutions with immense momentum (Lovell, 2007). The size of socio-technical infrastructures, determines the extent of inertia they exert. Researchers describe this inertia as technological lock-in (Schot et al., 1994; Unruh, 2002), entrapment
(Walker, 2000), path-dependency (Phillimore, 2001), drop in (Kemp, 1994), and continuity (Dosi, 1982). Regimes can encounter hurdles depending on the relationship that exists between them and the landscape factors. The reason behind the global campaign to consider alternative or renewable energy for unmet power markets is not solely that fossil fuel resources are finite. An excessive expansion in power capacity through fossil fuels, to promote access and end energy poverty, poses negative consequence on climate change efforts (Bazilian and Pielke, 2013). Such adverse repercussions tend to stifle the expansion of regime technology, and in the case of energy, result in current and future energy projects focusing more on renewable energy rather than intensive carbon energy. A decline in lock-in or path dependence of regimes technologies signals a broader adoption of renewable energy technologies.

\subsubsection{Niches}

Niche technologies can be defined as emerging innovations or technologies that develop to compete and potentially, or eventually, destabilize the regime configuration (Smith et al., 2010). Socio-technical niches develop in protective spaces from the excessive power of the socio-technical regimes (Hoogma et al., 2004). Niches face regime obstacles that are sometimes insurmountable resulting in a consequent fizzle-out before maturity. The high cost associated with niche technologies is often stated as a major obstacle in demand for such technologies (Geels, 2004a; Hoogma et al., 2004). When it comes to energy, however, the extensive institutional investment in research and development, the learning effect, and the gradual increase in renewable energy scale have contributed to a significant reduction in the unit cost of renewables (Kobos et al., 2006; McDonald and Schrattenholzer, 2001). The Global Fund is one such institution, which offers grants to nations advancing the use of renewable instead of fossil fuels, so that they can reduce the unit cost of renewables, making it more competitive (Martinot, 2000).

It is important to examine, critically, the three levels of the multilevel perspective, namely landscape, regime and niches, and their role in a potential transition pathway in unmet electricity markets. The development of niches and the growing landscape pressure in the energy sector, for instance, can be perceived as priming for the emergence and subsequent dominance of a potentially new socio-technical regime that would usher out the present regime.

\subsection{Innovation system}

The energy sector represents a collection of technical and social infrastructure that constitutes a system. The word 'system' is widely referenced in this paper and is usually connected with innovation, technology, energy, electricity, or other terms depicting the constitution of various components. A system is regarded by many scholars as a collection of components interconnected and interdependent on each other, and operating in synchrony towards an ultimate outcome (Bo Carlsson et al., 2002; Blanchard et al., 1990; Meadows, 2008; Bergek et al., 2008). The dynamics in a system depends on the number of interactions occurring within it.

Innovation systems augment the efficiency or performance of electricity systems through an innovation diffusion process, knowledge transfer, and learning. An innovation system refers to 'a network of actors and institutions that jointly interact in a specific technological field and contribute to the generation, diffusion, and utilisation of variants of a new technology and/or new product' (Markard and Truffer, 2008). It is considered that the collaboration or synergy of efforts or activities of individual entities in an industry or sector to develop and decentralise a technology (renewable energy technologies). An innovation system occurs under different settings or in different tiers, namely technological innovation (Carlsson, 2003; Carlsson and Stankiewicz, 1991; Markard and Truffer, 2008), national innovation (Freeman, 1995; Lundvall, 1992; Nelson, 1993), sectoral innovation (Breschi and 
Malerba, 1997; Geels, 2004a; Malerba, 2002), and regional innovation (Asheim and Coenen, 2005; Cooke et al., 1997; Kubeczko et al., 2006). Electricity provision is considered a complex system comprising multiple units working towards a common goal of generating and supplying electric power. The interconnectedness or interdependence of the subunits upon each other is significant and inseparable, and the output of their interdependence is greater than the sum of the units (Blanchard et al., 1990). Transformation in an electricity system involves one or a combination of tiers of innovation systems.

The ability to transition depends largely on the system of innovation. Even with the readiness of the end-user to transition, upstream innovation must be available for transition to occur. Transition in upstream supply also requires the readiness of end-users to respond or adapt commensurately. This implies that, at the time of the invention and development of a technology, innovators must recognise the market it seeks to serve, and end-users equally ought to be willing, or in the position to, accept and adapt this innovation as a unique, effective, efficient, and affordable technological alternative.

\subsection{Strategic Niche Management}

Niches emerge at the micro-level of the multi-level perspective (Geels, 2002). Depending on factors such as market conditions, and resilience of technology, niches can grow to catch up with regimes, or they may stagnate, or fizzle out of the market (Geels, 2002). To ensure that viable niche innovations are not crowded out before they are launched, they are developed and nurtured under protection until market conditions and the technology's value proposition can withstand existing market pressure (Geels and Schot, 2007). This process of nurturing and protection of niches is termed Strategic Niche Management. This involves monitoring and evaluating the strengths and weaknesses of an emerging innovation and juxtaposing that with prevailing market conditions to test its viability (Geels, 2002).

The fundamental underpinning of Strategic Niche Management is that, given the immense competitive capability of the regime, niche innovations require a protected space where they can be incubated and nurtured to maturity through a process of experimentation and learning by a network of different actors, including private and public organisations, producers, end-users, and researchers (Caniëls and Romijn, 2006). Amid abundant regime technologies, radical innovations encounter strong resistance from the market environment. This resistance spans technological factors such as the need for complementary technologies to use the new technology; cultural and psychological negativity resulting from insufficient information, and infrastructural factors including the distribution and communication networks; or the large sunk cost of the new technology. Others are the environmental factors including pollution and other repressive waste related issues: to regulatory limitations such as the lack of political will to offer incentives for the adoption of niche technologies (Kemp et al., 1998). The reason for keeping niche technologies in a protected space is to ensure that they are able to overcome the inertia new technologies usually encounter, which consequently cause their failure (Caniëls and Romijn, 2006).

Through Strategic Niche Management, stakeholders at local, regional, national, or even global level can nurture niche technologies by protecting them from the hostile competitive environment (Geels, 2002). In an unmet electricity market such as Africa, there is an already unsatisfied demand, which implies low market saturation and less competition on the supply side, except in cost. Government could introduce subsidies, for example, as one of the protection mechanisms for niche energy technologies.

\section{Theoretical foundations of the transition frameworks}

It is also important to recognise the complexity and evolutionary nature of infrastructural transition. The theory of complex systems
(Ethiraj and Levinthal, 2004; Kay et al., 1999; Rotmans and Loorbach, 2009; Arthur et al., 1997; Kauffman, 1990; Rotmans, 2003) and that of evolutionary systems (Foxon, 2011; Safarzyńska et al., 2012; van den Bergh, 2007; Safarzynska and van den Bergh, 2008) are rooted in how these frameworks emerge.

Discourse on the transition period is also found in other academic concepts and disciplines, such as socio-technical transition (Kern, 2012; Smith et al., 2010), ecological modernisation (Buttel, 2000; Hajer, 1995; York and Rosa, 2003) sociology (Lutzenhiser, 1992; Walker, 2014) and political ecology (Bridge, 2008; Smith et al., 2014; Sovacool and Linnér, 2015). These concepts and disciplines support the argument by Grubler (2012) and Smil (2010), who maintain that a long period is required for significant transition to occur.

\section{Limitations of present energy transition frameworks in African context}

Sustainable transition involves the interplay of technology, regulatory frameworks, society, and the market environment. Addressing the multi-dimensionality of sustainable transition and structural change requires theoretical approaches (Geels, 2011). The theoretical underpinnings of present transition frameworks are based on developed countries, which differ in their characteristics from developing countries. From the multi-level perspective (Geels, 2002; Geels and Schot, 2007) to transition management (Kemp et al., 2007a; Rotmans et al., 2001), technology innovation systems (Carlsson and Stankiewicz, 1991; Hekkert et al., 2007), through to the Strategic Niche Management (Kemp and Rip, 1998; Smith, 2007), these frameworks are primarily contextualised and largely applied in developed countries. Adopting them for developing countries would require adjustment to ensure their applicability. This section identifies and discusses key aspects to consider in the application of these transition frameworks, particularly the multi-level perspective, which encapsulates key elements of transition, in the context of developing countries. These are: (i) fulfilled, versus unmet, power market; (ii) large-scale versus small scale; (iii) fossil, versus renewable, energy; (iv) time aspect: slow or fast transition; (v) diminishing return versus niche opportunities, and (vi) single, versus multi-dimensional, pressures. These key aspects are further elaborated in the subsections that follow.

\subsection{Fulfilled versus unmet power market}

A fulfilled market refers to the extent to which access to electricity is met in developed countries, as opposed to the limited access found in developing countries. While the existing transition paradigms in energy are built based on a locked-in fossil regime, the deficit in energy services has not been clearly considered in research focused on unravelling potential transition pathways to sustainable energy sources. The reason can partly be attributed to the fact that the frameworks were developed in a context where electricity markets' demands are satisfied. In Africa, however, the size of the unmet power market is approximately $60 \%$ of the population, equivalent to about 600 million people (Scott, 2015), offering a vast opportunity for niche energy innovations to flourish. In the absence of conventional path dependent energy infrastructure, there is limited friction on renewable energy growth, hence a bigger opportunity for unmet markets to adopt contemporary renewable energy technologies.

The low percentage of access to electricity in Africa, largely subSaharan Africa (Scott, 2015), is indicative of the vastly unsatisfied market, which is uncommon in developed countries. Developing countries, by nature of their unmet power market, small-scale energy infrastructure, and underdeveloped electricity systems, may face fewer impediments in adapting novel energy technologies, and consequently, less path-dependence than their developed counterparts, who experience lock-in (Iizuka, 2014). This postulation is however contingent on the assumption that the political and socio-cultural issues that could 
cause transition inertia are averted. A transition from traditional energy sources such as biomass, to commercial fuels such as liquefied petroleum, gas and electricity, is an advancement that improves the standard of living and social well-being (Barnes and Floor, 2003; Leach, 1992). This could reduce potential political and socio-cultural obstacles to transition.

The Sustainable Development Goals (UN, 2015) advocates for the inclusion of renewable energy in the electricity generation energy mix in pursuit of universal access to modern energy (Giner-Reichl, 2015). Further, the renewed commitments during the COP21 in 2015 and most recently COP24 in 2018 to, proactively, mitigate the climatic effect of $\mathrm{CO}_{2}$ emissions strengthens the argument that regimes are facing pressures on two fronts, namely: landscape factors and emerging niches. Hence, the potential of niche technologies, such as renewable energy, being adopted at a faster rate in the unmet electricity markets is profound.

\subsection{Large-scale versus small-scale differences in power markets}

Large-scale refers to the scale of energy infrastructure that exists in developed countries in relation to the small-scale and underdeveloped energy infrastructure that characterises developing countries, especially in Africa. Developed countries have large-scale energy infrastructure, which presents a transition challenge that developing countries do not encounter. Smil (2010) observes that 'Energy transitions have been, and will continue to be, inherently prolonged affairs, particularly so in large nations whose high levels of per capita energy use and whose massive and expensive infrastructures make it impossible to greatly accelerate their progress even if we were to resort to some highly effective interventions.' This, in part, highlights the fact that, by sheer size of present regime infrastructure, developed countries' transition to renewable energy would occur at a slower rate than that of developing countries, which lack adequate electricity infrastructure. It is thus possible for energy transition to occur much more rapidly (Sovacool, 2016) in developing countries.

\subsection{Fossil versus renewable energy focus}

Fossil versus renewable refers to the choice between fossil fuels and renewable energy in electricity transition. The opportunities and challenges that characterise transitions from one fossil energy source to another differ from that of a transition from fossil fuel to renewable energy. Despite the challenges associated with knowledge transfer and information dissemination, when it comes to energy transition in the twenty-first century, there are shared global goals, which, in conjunction with the external landscape, facilitate transition in some areas and sectors. Sustainable transition is fast gaining popularity in sectors including energy, transport, and agriculture, as activities in these sectors directly relate to the environment, which is currently the focus of a variety of sustainability campaigns. The pioneers of sustainable transition in the twenty-first century are not the large firms championing regime technologies, but rather a new set of firms with strong commitments to sustainability as a core objective. However, in the absence of concentrated regime technologies, as is the case in unmet electricity markets, sustainability driven enterprises encounter little market friction.

The growing energy needs coupled with the negative consequences of fossil fuel on climate change (Bazilian and Pielke, 2013), would not only make renewable energy a sustainable choice but possibly obligatory, hence the potential for fluidity in transition. Renewable energy opportunities can also be harnessed on smaller scale, a practice common in Germany, where over half of the installed renewable electricity generation capacity belongs to individual citizens and farmers who live close to the power plants (Schmid et al., 2016). Electricity through photovoltaic solar energy storage, for example, is most advocated in contemporary discourse, due to the high possibility of tapping power from small rooftop to mini-grid systems. This can be attributed to the quick advancement of knowledge in solar technology and the large-scale opportunities for harnessing solar power in many parts of the globe.

\subsection{Slow versus fast transition time}

According to Sovacool (2016), whether or not a transition in an energy system takes a long time to realise, depends on the definition ascribed to it. Therefore, before discussing the limitations of time concept in present energy and socio-technical transition frameworks in an unmet electricity market context, key terms namely significant transition, society, and resources and services are defined because they are essential in energy transition (Sovacool, 2016). Transition in the dimension of time is assessed on this basis. The purpose of defining these key terms is to limit ambiguity and ensure clarity of scope, and also in response to the recommendation of Sovacool (2016) and Laird (2013), who observed that assumptions contained in definitions are not always clear, though important in demonstrating the design and representation of transitions.

While some scholars (Fouquet, 2010; Grubler, 2012; Smil, 2010) are reserved about energy transition and its implications, others (Sovacool, 2016; UN, 2015) are optimists and advocates of a radical transition. Grubler (2012) characterises quick introduction and instantaneous policies as detrimental in simulated innovation, with a predestined transition failure resulting within the new technology deployment arena, and cautions that it takes decades for innovation success to occur. He argues that the size of existing infrastructure makes transition in the sector slow. This observation is relevant to the extent that largescale energy infrastructure exists within the society or context in reference. In an unmet market, such as Africa, energy infrastructure is relatively small or non-existent, hence the potential for transition to occur faster. Sovacool (2016) supported this, affirming, that energy transition has, and can, occur in a shorter time than predicted, although it may remain inconspicuous unless assessed based on a given significance, society, and energy resource and services. Pre-existing niche markets could be a catalyst for propelling adoption of innovation in a shorter time (Grubler, 2012).

It is clear, therefore, that the dynamics and pace of technology acceptance in a fulfilled market differs from those of a market with unmet demand. The major difference pertains to infrastructural characteristics - large-scale lock-in for a fully satisfied market versus limited or no 'regime' technologies acting as inertia to niche technologies adoption in an unmet market. Given their relatively underdeveloped energy infrastructure, developing economies experience transition at a faster rate and across a broader spectrum of energy sources (Marcotullio and Schulz, 2007). Some major drivers of transition, such as urbanisation, income, education, running water, fuel prices, electrification, and the difficulty in accessing traditional fuels, propel the rate of transition in energy sources (Heltberg, 2004; Pachauri and Jiang, 2008). Given the broad range of services that electricity provides, compared to the services from traditional energy sources, there should be an increase in the willingness and rate of acceptance of transition in energy for household and other commercial needs, and subsequently, an increase in the transition rate in unmet markets.

\subsection{Diminishing returns versus emerging niche opportunities}

Diminishing returns here implies the change in marginal return of electricity consumed from the newly adopted energy alternative. In developed countries, because of the fully satisfied demand, there is little or no marginal return on a unit of energy consumed. In developing countries, however, the unmet power market creates a higher marginal return on electricity, hence a higher tendency to accept the introduction of alternative energy. Conventional economics (Fiddaman, 2002; Hall and Klitgaard, 2011; Tainter, 1990) generally fail to notice the close 
association between a resource, such as energy, and the economy. This is because of the misperception that fossil fuel is available in abundance and, although energy is considered an economic production factor, the possibility of it being inaccessible is not recognised (Sgouridis and Csala, 2014). The pre-existence of niche markets in developing countries is an opportunity for experimenting and scaling up new technologies (Grubler, 2012). With technological, national, regional, and sectoral innovations, the advancement of niche opportunities amidst the vast unmet market could propel the rate of transition.

The marginal return for niche opportunities in an unmet market offers significant incentive for transition to occur quickly. In response to criticisms of the multi-level perspective, Geels (2011) contends that the incentive for the private sector in sustainable transition is low. Though this could easily be thought of as a universal experience in the energy market, in many deregulated electricity markets, e.g. Europe, where there are incentives, active private sector participation exists. Many independent power producers fall into this category because of state support in the form of a subsidy and feed-in-tariffs.

\subsection{Single versus multi-dimensional influence}

It is important to acknowledge that, in existing energy markets, the pressure to transition from the fossil regime to renewable energy is not merely that of landscape activities in the form of international emission regulations, but also the emerging rapid niche growth supported by landscape investments. This is not exactly the same as an intra-regime shift, such as the transition from coal to oil-based infrastructure. With limited external pressure on investors to act, transition in such a context can be sluggish. This observation, though not necessarily unique to unmet electricity markets, is not clearly demonstrated in present transition frameworks. The inadequate supply of electricity also creates a novel influence, distinguishable from that of landscape. This is demandpull, which increases incentive for investors in niche technologies, especially when backed by statutory guarantees. There is demand for diversified energy services in Africa. Despite the limited electricity access, there is wide adoption of modern technologies, such as mobile phones, which cannot be powered as easily or inexpensively by traditional energy. This technology adoption pattern increases the demand for electricity, and presents an opportunity for the introduction of some form of renewable energy as an alternative for accelerating electricity access.

\section{Modified transition framework for unmet electricity markets}

The inaptness of existing transition frameworks for the unmet electricity markets is illustrated by the limitations discussed in section 5. A modified transition framework was designed upon a series of queries on the existing frameworks and the unmet African market context. The first query was to establish if any of the transition frameworks fully represent the energy technology clusters that are being used in Africa. None of the frameworks captured all the technology clusters. The second query was whether the transition frameworks adequately represents the African case. Upon discussing the limitations of the existing transition frameworks, a contextual limitation in applying these frameworks in Africa became apparent. The third query was to identify the key elements missing in the existing frameworks. The traditional technology curve, and the support that landscapes give to niches were missing in the existing frameworks. Other features such as the different dynamics in the interaction of these technologies were not obvious. A modified transition framework, based off of the dynamic multi-level perspective of technological transitions by Geels (2002), was subsequently designed. The new transition framework accounts for the unique characteristics of the unmet electricity markets. This modified transition framework is shown in Fig. 2.

Although the dynamic multi-level perspective Fig. 2 could be suitably and universally applicable to transitions in fully met energy markets, it falls short of addressing the contextual peculiarities of the unmet energy markets. One major limitation of the multi-level perspective framework is that it fails to recognise that traditional energy is still largely used in unmet electricity markets, and therefore omits the traditional energy or technology curve (see Fig. 2). When it comes to unmet markets, therefore, a key piece of information is missing in the contextualisation of the multi-level perspective and, to some degree, its scope of application. The key characteristics in the modified transition framework of the unmet electricity markets are: (i) traditional technology; (ii) defunct deceleration; (iii) the niche technology curve; (iv) the landscape's support for niches; (v) descent to defunct; and (vi) newregime condensation. These are further discussed in the sections that follow.

\subsection{Traditional technology}

The modified framework in Fig. 2 captures the existence of a traditional, old technology that is still in use in the unmet electricity markets where regime technologies are lacking. Given that regime technologies are already under transition, with the emergence of niches, this is the ideal opportunity to leapfrog the unmet markets into niche technologies. This could be either path creating or path skipping leapfrogging, depending on market characteristics and origin of the innovation. The goal is to avoid path-following leapfrogging or worse, technological obsolescence as is the case with old technology in unmet markets.

\subsection{Defunct deceleration}

The interaction of traditional and niche technology curves creates a temporal technological instability, which presents opportunity for the unmet market to leapfrog the regime technology to niche technology. The traditional technology curve would experience a rapid deceleration after it intersects with the niche technology curve. This deceleration is termed the defunct deceleration, as new adopters recognise the modernity and extended benefits of the niche technology, compared to the traditional technology or even existing regime technologies. The defunct technologies often do not entirely disappear. Developed countries, for example, continue to consume energy from wood as a vintage technology with unique novelty. This is different from developing countries or unmet energy markets, where traditional energy sources such as wood remain the major energy resource, the excessive consumption of which creates adverse environmental effects, such as deforestation and acceleration of negative climatic conditions.

\subsection{Niche technology curve}

The steepness of the niche innovation curve also highlights the understanding that the rate of innovation, adoption, and landscape pressure and/or support therefore, is one major determinant of the lifespan of present technology. Given the vastly unmet market size, niche technology acceptance and adoption leads to a quick take-off and allows it to capture a large part of the technology market. This is inconsistent in the case of a near-saturation market, as captured in Geels (2002) framework, where niche innovation grows rather slowly because of extensive regime competition.

\subsection{Landscape support for niches}

Another limitation of the multi-level perspective framework is the fact that it does not consider the support that niches receive from landscape development, when it comes to energy transition. Although it appropriately captures the pressures that landscapes such as COP21, Paris Agreement, Copenhagen Accord, among others, exert on conventional regime technologies to transition, when it comes to the support these landscapes extend to propelling the growth of niche 


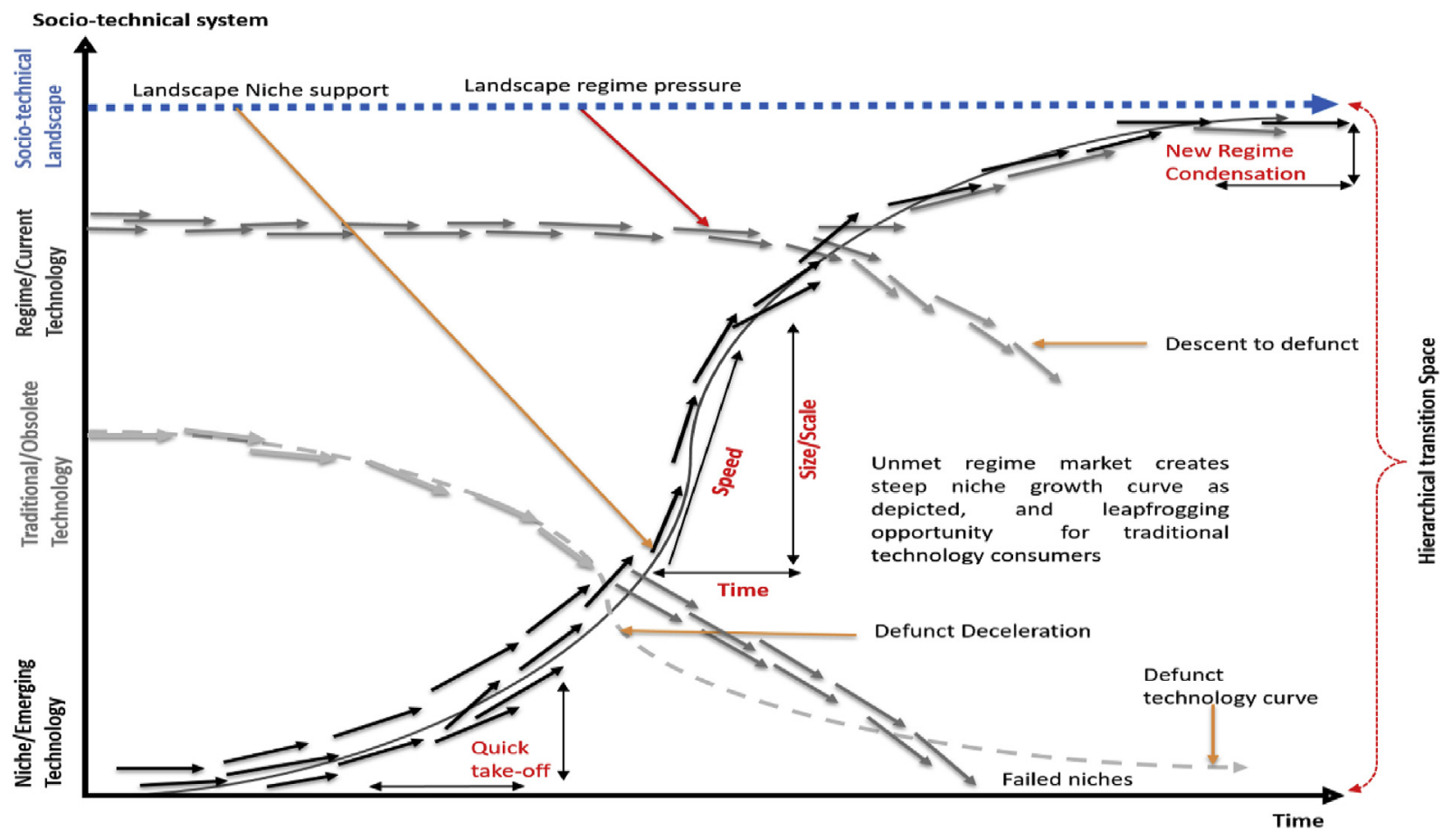

Fig. 2. Transition framework for unmet electricity markets.

innovation, the framework is limited. The modified framework, therefore, recognises this bi-dimensional landscape effect on regimes and niches. Landscapes, besides pressurising regimes to transition, also support the nurturing and dominance of niches such as renewable energy technologies. Beyond transitions in the energy sector, or situations where landscapes do not favour niche creation (Geels, 2002), the innovation system framework would remain suitable.

\subsection{Descent to defunct}

Another feature of the modified multi-level innovation systems is that, when regime technologies do interact with the niche technologies, a significant number of the regime technologies would descend towards the defunct curve, because the niche technologies have gained ground and acquired a strong competitive advantage. The regime technologies that survive the niche interactions, especially in an unmet market, would largely consist of those with established large-scale infrastructure. For instance, given that Africa contains large unmet markets, and that those with access to modern energy received that access only recently, the introduction of niche technologies in the satisfied market would result in a gradual decline in regime technologies, especially if investment were limited. On the other hand, they could encounter pathfollowing leapfrogging by adopting niche technologies within a short time of first using regime technologies. The rate and size at which the regime declines to defunct status depends on the benefits of the niche technology, and the length of time the regime technology is in use.

\subsection{New regime condensation}

After a socio-technical regime interacts with niche technologies, a new regime cluster eventually emerges. This clustering of technologies, following a peak competition for dominance, is termed a regime condensation. It is expected that the new regime cluster would consist mainly of the present niche technology. It takes time for niche technologies to form a dominant regime cluster. The size of present regime technologies in the new condensation is a function of their resilience, the benefits of the niche technology, and the landscape's attitude towards such technologies.

\section{Conclusion and policy implications}

Energy transition, in the context of developing countries in other parts of the world, may not necessarily be the same as in Africa, irrespective of the extensive features they may share. A strong distinguishable feature could be all that matters in making for dynamic social and infrastructural systems contextually inapplicable. Adopting developed countries' energy transition frameworks for developing countries would require adjustment to ensure their applicability. The abundance of renewable energy resources across an unmet electricity market, such as that in Africa, presents the opportunity for a unique transition framework for analysis of a situation and the transition to renewable energy technology. This study identified five key distinctions between the energy transition contexts of developed and developing countries, namely: (i) fulfilled versus unmet power market; (ii) large-scale versus small scale; (iii) fossil versus renewable; (iv) time aspect - slow or fast; and (v) diminishing return versus niche opportunities. The limitations embedded in current transition frameworks are a clear indication of their unsuitability for unmet electricity markets. A modified transition framework that accounts for the unique characteristics of the unmet electricity markets was developed, which includes these characteristics: (i) traditional technology; (ii) defunct deceleration; (iii) the niche technology curve; (iv) landscape support for niches; and (v) new regime condensation.

The limitations of existing transition frameworks, the unique features of the unmet electricity markets, and the eventual transition framework presented in this study demonstrate that energy transition in sub-Saharan Africa can occur rapidly. This study is not oblivious to the competing hypotheses that political and socio-cultural barriers can undermine transition in unmet energy markets. Given the large unmet market size and rising environmental concerns, developing countries can, and should, avoid the mundane pattern of transition in energy system by leapfrogging to renewable energy for electricity services.

This study established that, energy transition in unmet electricity markets, unlike that of developed markets, involves three distinct technologies: traditional (old), niche (emerging), and regime (present). Implementation of transition in the unmet electricity markets can therefore occur in two ways: from traditional to regime, or from regime 
to niche. However, the markets in the traditional energy arena can leapfrog to niche technologies (see Batinge et al., 2017) without going through regime technologies because of the low path-dependence due created by the lack of conventional energy infrastructure. We however acknowledge that political and socio-cultural norms can still serve as lock-ins, and inhibit leapfrogging.

Further empirical research should test the robustness of this framework, and investigate the possible political, economic and sociocultural lock-in the framework may encounter, especially at a national level. Indeed, the search parameters, though broad, does not imply that all literature pertaining to energy was captured. While a search of all databases appears impossible to accomplish, we recommend that future research expand the search scope to include other databases that are not included in this study. The search terms may also eliminate certain literature on transition frameworks. We further recommend that future studies consider a wider search term combinations than what this study has accomplished, and also extend the language of coverage if possible.

\section{Acknowledgement}

This study was part of a research project supported by the Graduate School of Economic and Management Sciences at Stellenbosch University.

\section{References}

Ackerman, L.S., 1982. Transition management: an in-depth look at managing complex change. Organ. Dynam. 11, 46-66.

Adler, G., Webster, E., 1995. Challenging transition theory: the labor movement, radical reform, and transition to democracy in South Africa. Polit. Soc. 23 75-75.

Araújo, K., 2014. The emerging field of energy transitions: progress, challenges, and opportunities. Energy Res. Soc. Sci. 1, 112-121.

Arthur, W.B., Durlauf, S.N., Lane, D.A., 1997. The Economy as an Evolving Complex System II. Addison-Wesley, Reading, MA.

Asheim, B.T., Coenen, L., 2005. Knowledge bases and regional innovation systems: comparing Nordic clusters. Res. Policy 34, 1173-1190.

Barnes, D.F., Floor, W.M., 2003. Rural energy in developing countries: a challenge for economic Development 1. Annu. Rev. Energy Environ. 21, 497.

Batinge, B., Musango, J.K., Brent, A.C., 2017. Leapfrogging to renewable energy: the opportunity for unmet electricity markets. S. Afr. J. Ind. Eng. 28 (4), 32-49.

Bazilian, M., Pielke Jr., R., 2013. Making energy access meaningful. Issues Sci. Technol. $29,74$.

Bergek, A., Jacobsson, S., Carlsson, B., Lindmark, S., Rickne, A., 2008. Analyzing the functional dynamics of technological innovation systems: a scheme of analysis. Res. Policy 37, 407-429.

Blanchard, B.S., Fabrycky, W.J., Fabrycky, W.J., 1990. Systems Engineering and Analysis. Prentice Hall, New Jersey.

Bo Carlsson, S.J., Holmén, Magnus, Rickne, Annika, 2002. Innovation systems: analytical and methodological issues. Res. Policy 31, 233-245.

Breschi, S., Malerba, F., 1997. Sectoral Innovation Systems: Technological Regimes, Schumpeterian Dynamics, and Spatial Boundaries.

Bridge, G., 2008. Environmental economic geography: a sympathetic critique. Geoforum 39, 76-81.

Buttel, F.H., 2000. Ecological modernization as social theory. Geoforum 31, 57-65.

Caldwell, J.C., 1976. Toward a restatement of demographic transition theory. Popul. Dev. Rev. 321-366.

Callon, M., 1999. Actor-network theory-the market test. Socio. Rev. 47, 181-195.

Caniëls, M., Romijn, H., 2006. Strategic Niche Management as an operational tool for sustainable innovation: guidelines for practice. In: Schumpeter Conference, pp. $21-24$.

Carlsson, B., 2003. Innovation Systems: a Survey of the Literature from a Schumpeterian Perspective. Paper for the Elgar Companion to Neo-Schumpeterian Economics June.

Carlsson, B., Jacobsson, S., Holmén, M., Rickne, A., 2002. Innovation systems: analytical and methodological issues. Res. Policy 31, 233-245.

Carlsson, B., Stankiewicz, R., 1991. On the nature, function and composition of technological systems. J. Evol. Econ. 1, 93-118.

Chappin, E.J., Dijkema, G.P., 2010. Agent-based modelling of energy infrastructure transitions. Int. J. Crit. Infrastruct. 6, 106-130.

Chesnais, J.-C., 1992. The Demographic Transition: Stages, Patterns, and Economic Implications. OUP Catalogue.

Cooke, P., Mikel, G.U., Goio, E., 1997. Regional innovation systems: institutional and organisational dimensions. Res. Policy 26, 475-491.

Davison, R., Vogel, D., Harris, R., Jones, N., 2000. Technology leapfrogging in developing countries-an inevitable luxury? Electron. J. Inf. Syst. Dev. Ctries. 1, 1-10.

De Soysa, I., Oneal, J.R., Park, Y.-H., 1997. Testing power-transition theory using alternative measures of national capabilities. J. Confl. Resolut. 41, 509-528.

Dijkema, G.P.J., Basson, L., 2009. Complexity and industrial ecology. J. Ind. Ecol. 13, 157-164.
Dosi, G., 1982. Technological paradigms and technological trajectories: a suggested interpretation of the determinants and directions of technical change. Res. Policy 11, 147-162.

Edquist, C., 2011. Systems of innovation: perspectives and challenges. Afr. J. Sci. Technol. Innov. Dev. (AJSTID) 2, 14-43.

Elzen, B., Geels, F.W., Green, K., 2004. System Innovation and the Transition to Sustainability: Theory, Evidence and Policy. Edward Elgar Publishing.

Ethiraj, S.K., Levinthal, D., 2004. Modularity and innovation in complex systems. Manag. Sci. 50, 159-173.

Fiddaman, T.S., 2002. Exploring policy options with a behavioral climate-economy model. Syst. Dynam. Rev. 243-267.

Fouquet, R., 2010. The slow search for solutions: lessons from historical energy transitions by sector and service. Energy Policy 38, 6586-6596.

Foxon, T.J., 2011. A coevolutionary framework for analysing a transition to a sustainable low carbon economy. Ecol. Econ. 70, 2258-2267.

Freeman, C., 1995. The 'National system of innovation'in historical perspective. Camb. J. Econ. 19, 5-24.

Frenk, J., Bobadilla, J.L., Stern, C., Frejka, T., Lozano, R., 1991. Elements for a theory of the health transition. Health Transit. Rev. 21-38.

Geels, F.W., 2002. Technological transitions as evolutionary reconfiguration processes: a multi-level perspective and a case-study. Res. Policy 31, 1257-1274.

Geels, F.W., 2004a. From sectoral systems of innovation to socio-technical systems: in sights about dynamics and change from sociology and institutional theory. Res. Policy 33, 897-920.

Geels, F.W., 2004b. Understanding System Innovations: a Critical Literature Review and a Conceptual Synthesis.

Geels, F.W., 2005a. Processes and patterns in transitions and system innovations: refining the co-evolutionary multi-level perspective. Technol. Forecast. Soc. Change 72, 681-696.

Geels, F.W., 2005b. Technological Transitions and System Innovations: a Co-evolutionary and Socio-Technical Analysis. Edward Elgar.

Geels, F.W., 2011. The multi-level perspective on sustainability transitions: responses to seven criticisms. Environ. Innov. Soc. Transit. 1, 24-40.

Geels, F.W., Schot, J., 2007. Typology of sociotechnical transition pathways. Res. Policy 36, 399-417.

Giddens, A., 2009. The Politics of Climate Change. Polity, Cambridge.

Giner-Reichl, I., 2015. Renewable energy in international and regional governance: propelling development in Africa. Energy Res. Soc. Sci. 5, 116-119.

Grubler, A., 2012. Energy transitions research: insights and cautionary tales. Energy Policy 50, 8-16.

Hajer, M.A., 1995. The Politics of Environmental Discourse: Ecological Modernization and the Policy Process. Clarendon Press, Oxford.

Hall, C.A., Klitgaard, K.A., 2011. Energy and the Wealth of Nations: Understanding the Biophysical Economy. Springer Science \& Business Media.

Hekkert, M.P., Suurs, R.A.A., Negro, S.O., Kuhlmann, S., Smits, R.E.H.M., 2007. Functions of innovation systems: a new approach for analysing technological change. Technol. Forecast. Soc. Change 74, 413-432.

Heltberg, R., 2004. Fuel switching: evidence from eight developing countries. Energy Econ. 26, 869-887.

Hoogma, R., Kemp, R., Schot, J., Truffer, B., 2004. Experimenting for Sustainable Transport: the Approach of Strategic Niche Management.

IEA, 2011. World Energy Outlook 2011. OECD/IEA, Paris.

Iizuka, M., 2014. Diverse and uneven pathways towards transition to low carbon development: the case of diffusion of solar PV technology in China. In: Maastricht Economic and Social Research Institute on Innovation and Technology. (UNUMERIT) \& Maastricht Graduate School of Governance.

Jacobsson, S., Bergek, A., 2011. Innovation system analyses and sustainability transitions: contributions and suggestions for research. Environ. Innov. Soc. Transit. 1, 41-57.

Kanagawa, M., Nakata, T., 2008. Assessment of access to electricity and the socio-economic impacts in rural areas of developing countries. Energy Policy 36, 2016-2029.

Kauffman, S.A., 1990. Requirements for evolvability in complex systems: orderly dynamics and frozen components. Phys. Nonlinear Phenom. 42, 135-152.

Kay, J.J., Regier, H.A., Boyle, M., Francis, G., 1999. An ecosystem approach for sustainability: addressing the challenge of complexity. Futures 31, 721-742.

Kemp, R., 1994. Technology and the transition to environmental sustainability: the problem of technological regime shifts. Futures 26, 1023-1046.

Kemp, R., 2010. The Dutch energy transition approach. Int. Econ. Econ. Policy 7, 291-316.

Kemp, R., Arie, R., Johan, S., 2001. Constructing transition paths through the management of niches. In: Path Dependence and Creation. Lawrence Erlbaum.

Kemp, R., Loorbach, D., Rotmans, J., 2007a. Transition management as a model for managing processes of co-evolution towards sustainable development. Int. J. Sustain. Dev. World Ecol. 14, 78-91.

Kemp, R., Rip, A., 1998. Technological change. In: Raynor, S., Malone, E.L. (Eds.), Human Choice and Climate Change. Battelle Press, Columbus.

Kemp, R., Rotmans, J., Loorbach, D., 2007b. Assessing the Dutch energy transition policy: how does it deal with dilemmas of managing transitions? J. Environ. Policy Plan. 9, 315-331.

Kemp, R., Schot, J., Hoogma, R., 1998. Regime shifts to sustainability through processes of niche formation: the approach of strategic Niche management. Technol. Anal. Strat. Manag. 10, 175-198.

Kern, F., 2012. Using the multi-level perspective on socio-technical transitions to assess innovation policy. Technol. Forecast. Soc. Change 79, 298-310.

Kern, F., Smith, A., 2008. Restructuring energy systems for sustainability? Energy transition policy in The Netherlands. Energy Policy 36, 4093-4103.

Kirk, D., 1996. Demographic transition theory. Popul. Stud. 50, 361-387. 
Kobos, P.H., Erickson, J.D., Drennen, T.E., 2006. Technological learning and renewable energy costs: implications for US renewable energy policy. Energy Policy 34, $1645-1658$.

Kubeczko, K., Rametsteiner, E., Weiss, G., 2006. The role of sectoral and regional innovation systems in supporting innovations in forestry. For. Policy Econ. 8, 704-715.

Laird, F.N., 2013. Against transitions? Uncovering conflicts in changing energy systems. Sci. Cult. 22, 149-156.

Law, J., 1992. Notes on the theory of the actor-network: ordering, strategy, and heterogeneity. Syst. Pract. 5, 379-393.

Leach, G., 1992. The energy transition. Energy Policy 116-123.

Lemke, D., Reed, W., 1996. Regime types and status quo evaluations: power transition theory and the democratic peace. Int. Interact. 22, 143-164.

Linz, J.J., Stepan, A., 1996. Problems of Democratic Transition and Consolidation: Southern Europe, South America, and Post-communist Europe. JHU Press, Baltimore.

Loorbach, D., 2010. Transition management for sustainable development: a prescriptive, complexity-based governance framework. Governance 23, 161-183.

Loorbach, D., Rotmans, J., 2010. The practice of transition management: examples and lessons from four distinct cases. Futures 42, 237-246.

Lovell, H., 2007. The governance of innovation in socio-technical systems: the difficulties of Strategic Niche Management in practice. Sci. Publ. Policy 34, 35-44.

Lundvall, B.-A., 1992. National Systems of Innovation: an Analytical Framework.

Lutzenhiser, L., 1992. A cultural model of household energy consumption. Energy 17, $47-60$.

Mackenbach, J., 1994. The epidemiologic transition theory. J. Epidemiol. Community Health 48, 329-331.

Malerba, F., 2002. Sectoral systems of innovation and production. Res. Policy 31, 247-264.

Marcotullio, P.J., Schulz, N.B., 2007. Comparison of energy transitions in the United States and developing and industrializing economies. World Dev. 35, 1650-1683.

Markard, J., Truffer, B., 2008. Technological innovation systems and the multi-level perspective: towards an integrated framework. Res. Policy 37, 596-615.

Martinot, E., 2000. Renewable Energy Markets and the Global Environment Facility. Financial Times, pp. 18-22 Renewable Energy Report.

McDonald, A., Schrattenholzer, L., 2001. Learning rates for energy technologies. Energy Policy 29, 255-261.

Meadowcroft, J., 2009. What about the politics? Sustainable development, transition management, and long term energy transitions. Pol. Sci. 42, 323-340.

Meadows, D.H., 2008. Thinking in Systems: A Primer. Chelsea Green Publishing.

Meadows, D.H., Meadows, D.L., Randers, J., Behrens, W.W., 1972. The Limits to Growth: a Report to the Club of Rome. Potomac Associates, New York.

Meir, A., 1986. Demographic transition theory: a neglected aspect of the nomadism-sedentarism continuum. Trans. Inst. Br. Geogr. 199-211.

Miller, C.A., Richter, J., O'Leary, J., 2015. Socio-energy systems design: a policy framework for energy transitions. Energy Res. Soc. Sci. 6, 29-40.

Mitchell, C.L., 2008. Altered landscapes, altered livelihoods: the shifting experience of informal waste collecting during Hanoi's urban transition. Geoforum 39, 2019-2029.

Nee, V., 1989. A theory of market transition: from redistribution to markets in state socialism. Am. Sociol. Rev, 663-681.

Nelson, R.R., 1993. National Innovation Systems: a Comparative Analysis. University Press.

Nielsen, J.R., Hovmøller, H., Blyth, P.-L., Sovacool, B.K., 2015. Of "white crows" an "cash savers:" A qualitative study of travel behavior and perceptions of ridesharing in Denmark. Transport. Res. Pol. Pract. 78, 113-123.

Offe, C., Adler, P., 1991. Capitalism by democratic design? Democratic theory facing the triple transition in East Central Europe. Soc. Res. 865-892

Omran, A.R., 1971. The epidemiologic transition: a theory of the epidemiology of population change. Milbank Mem. Fund. Q. 49, 509-538.

Pachauri, S., Jiang, L., 2008. The household energy transition in India and China. Energy Policy 36, 4022-4035.

Painuly, J.P., 2001. Barriers to renewable energy penetration; a framework for analysis. Renew. Energy 24, 73-89.

Pearce, D.W., Markandya, A., Barbier, E., 1989. Blueprint for a Green Economy. Earth scan Publication Limited, London.

Phillimore, J., 2001. Schumpeter, Schumacher and the greening of technology. Technol. Anal. Strat. Manag. 13, 23-37.

Raven, R., Geels, F., 2010. Socio-cognitive evolution in niche development: comparative analysis of biogas development in Denmark and The Netherlands (1973-2004). Technovation 30, 87-99.

Roland, G., 2002. The political economy of transition. J. Econ. Perspect. 16, 29-50.

Rotmans, J., 2003. Transition Management: Key to a Sustainable Society. Assen Van Gorcum.

Rotmans, J., Kemp, R., van Asselt, M., 2001. More evolution than revolution: transition management in public policy. Foresight 3, 15-31.

Rotmans, J., Loorbach, D., 2009. Complexity and transition management. J. Ind. Ecol. 13, 184-196.

Safarzyńska, K., Frenken, K., van den Bergh, J.C., 2012. Evolutionary theorizing and modeling of sustainability transitions. Res. Policy 41, 1011-1024.

Safarzynska, K., van den Bergh, J.C., 2008. Evolutionary Modelling in Economics: a Survey of Methods and Building Blocks. (The Papers on Economics and Evolution).

Sarrica, M., Brondi, S., Cottone, P., Mazzara, B.M., 2016. One, no one, one hundred thousand energy transitions in Europe: the quest for a cultural approach. Energy Res. Soc. Sci. 13, 1-14.

Schmid, E., Knopf, B., Pechan, A., 2016. Putting an energy system transformation into practice: the case of the German Energiewende. Energy Res. Soc. Sci. 11, 263-275.

Schot, J., Hoogma, R., Elzen, B., 1994. Strategies for shifting technological systems: the case of the automobile system. Futures 26, 1060-1076.

Scott, A., 2015. Building Electricity Supplies in Africa for Growth and Universal Access. The New Climate Economy Working Paper.

Sgouridis, S., Csala, D., 2014. A framework for defining sustainable energy transitions: principles, dynamics, and implications. Sustainability 6, 2601-2622.

Shackley, S., Green, K., 2007. A conceptual framework for exploring transitions to decarbonised energy systems in the United Kingdom. Energy 32, 221-236.

Smil, V., 2010. Energy Transitions: History, Requirements, Prospects. ABC-CLIO, Santa Barbara.

Smith, A., 2007. Translating sustainabilities between green niches and socio-technical regimes. Technol. Anal. Strat. Manag. 19, 427-450.

Smith, A., Kern, F., Raven, R., Verhees, B., 2014. Spaces for sustainable innovation: solar photovoltaic electricity in the UK. Technol. Forecast. Soc. Change 81, 115-130.

Smith, A., Voß, J.-P., Grin, J., 2010. Innovation studies and sustainability transitions: the allure of the multi-level perspective and its challenges. Res. Policy 39, 435-448.

Sovacool, B.K., 2009. Rejecting renewables: the socio-technical impediments to renewable electricity in the United States. Energy Policy 37, 4500-4513.

Sovacool, B.K., 2016. How long will it take? Conceptualizing the temporal dynamics of energy transitions. Energy Res. Soc. Sci. 13, 202-215.

Sovacool, B.K., Hirsh, R.F., 2009. Beyond batteries: an examination of the benefits and barriers to plug-in hybrid electric vehicles (PHEVs) and a vehicle-to-grid (V2G) transition. Energy Policy 37, 1095-1103.

Sovacool, B.K., Linnér, B.-O., 2015. The Political Economy of Climate Change Adaptation. Palgrave Macmillan, Basingstoke.

Tainter, J., 1990. The Collapse of Complex Societies. Cambridge University Press, Cambridge.

Tukker, A., 2005. Leapfrogging into the future: developing for sustainability. Int. J. Innov. Sustain. Dev. 1, 65-84.

UNFCCC, C., 1992. United Nations Framework Convention on Climate Change. Kyoto Protocol. UN, Kyoto.

UN, 2015. In: Conference of the Parties, Framework Convention on Climate Change. UN, Paris.

Unruh, G.C., 2002. Escaping carbon lock-in. Energy Policy 30, 317-325.

van den Bergh, J.C., 2007. Evolutionary thinking in environmental economics. J. Evol. Econ. 17, 521-549.

Verbong, G.P.J., Geels, F.W., 2010. Exploring sustainability transitions in the electricity sector with socio-technical pathways. Technol. Forecast. Soc. Change 77, 1214-1221.

Walker, G., 2014. The dynamics of energy demand: change, rhythm and synchronicity. Energy Res. Soc. Sci. 1, 49-55.

Walker, W., 2000. Entrapment in large technology systems: institutional commitment and power relations. Res. Policy 29, 833-846.

Weitzman, M.L., 1993. Economic transition: can theory help? Eur. Econ. Rev. 37, 549-555.

York, R., Rosa, E.A., 2003. Key challenges to ecological modernization theory institutional efficacy, case study evidence, units of analysis, and the pace of eco-efficiency. Organ. Environ. 16, 273-288. 